\title{
EL ESPAÑOL DE PUERTO RICO: PERCEPCIONES DIALECTALES Y ACTITUDES LINGÜÍSTICAS
}

\author{
Roxana Sobrino Triana \\ Universidad de Bergen \\ roxanasobrino@gmail.com
}

\begin{abstract}
RESUMEN: En el artículo se analizan las percepciones dialectales y las actitudes lingüisticas de los hablantes puertorriqueños con respecto a su variedad de español. Desde los postulados teóricos de la dialectología perceptual y las actitudes lingüisticas como disciplinas, se profundiza en las percepciones, creencias, valoraciones y reacciones de los hablantes de esta variedad de español. Específicamente, la investigación se centra en el modo en que los puertorriqueños perciben su propia modalidad de lengua en el mundo hispanohablante, las similitudes y diferencias que establecen con respecto a otras variantes de español, los rasgos a través de los cuales se auto caracterizan lingüísticamente y las actitudes que manifiestan. Los datos se obtuvieron a partir de la aplicación de un cuestionario en el Área Metropolitana de Puerto Rico a una muestra de cincuenta y cuatro informantes, estratificada según las variables sociolingüisticas sexo, edad y nivel de instrucción.

PALABRAS CLAVE: español de Puerto Rico, actitudes lingüisticas, percepciones dialectales.
\end{abstract}

\section{THE SPANISH OF PUERTO RICO: DIALECTAL PERCEPTIONS AND LINGUISTIC ATTITUDES}

ABSTRACT: The article analyzes the dialect perceptions and linguistic attitudes of Puerto Rican speakers regarding their variety of Spanish. From the theoretical postulates of perceptual dialectology and linguistic attitudes as disciplines, the perceptions, beliefs, evaluations and reactions of the speakers of this variety of Spanish are deepened. Specifically, the research focuses on how Puerto Ricans perceive their own mode of language in the Spanish-speaking world, the similarities and differences they establish with respect to other variants of Spanish, the traits through which they self-characterize linguistically and the attitudes that manifest. The data were obtained from the application of a questionnaire in the Metropolitan Area of Puerto Rico to a sample of fifty-four informants, stratified according to sociolinguistic variables gender, age and level of education.

KEYWORDS: Spanish of Puerto Rico, linguistic attitudes, dialectal perceptions.

Recibido: 13/10/2017. Aceptado: 08/02/2018 


\section{Introducción}

El español puertorriqueño es una de las variedades que conforman la zona dialectal caribeña del español que, desde la dialectología tradicional, se ha descrito como un área con límites continentales imprecisos, pero de la cual las Antillas hispanohablantes constituyen su centro neurálgico e indiscutible (Zamora y Guitart 1988; López Morales 1992: 295).

Desde el punto de vista fónico se caracteriza por un fuerte vocalismo, consonantismo final débil, sobre todo en cuanto a la realización de los fonemas caracterizadores /s/, /R/, /1/, debilitamiento de /d/ intervocálica, velarización de $/ \mathrm{n} /$, entre otros. A estos deben añadirse otros rasgos compartidos con gran parte de los hispanohablantes como el seseo, el yeísmo o la aspiración faríngea de la consonante velar y otros que, por su alta frecuencia de aparición en la variedad puertorriqueña, se han convertido en elementos distinguidores del habla del país (Alba 1992: 525 y ss.; López Morales 1992; Vaquero 1996: 60-61; Domínguez 2000; Lipski 2004; Moreno 2009). Es el caso de la lateralización y velarización del fonema $/ \mathrm{r}$, este último más propio de zonas montañosas y menos extendido en la Zona Metropolitana, así como un fenómeno de más reciente estudio que es la oclusión glotal de /s/, más frecuente en el habla de mujeres y adolescentes (Vaquero 1991; Morales 2000; Valentín-Márquez 2006).

La influencia del inglés en el español de Puerto Rico, condicionada por la situación política con respecto a Estados Unidos que vive la isla desde fines del siglo $\mathrm{XX}$, ha sido uno de los aspectos más estudiados sobre esta modalidad de lengua. En el nivel léxico, una investigación sobre léxico disponible dio cuenta de que el 8,1\% del total de voces recogidas eran anglicismos (López Morales 1999). En cuanto a la morfosintaxis, algunas estructuras también han sido asociadas con posibles interferencias o transferencias ${ }^{1}$ del inglés como es el caso de la presencia de sujetos pronominales y el mantenimiento de la estructura SVO (sujeto + verbo + objeto) incluso en oraciones interrogativas (¿Dónde tú vives?, ¿Cómo tú estás?); estructuras de gerundio con función adjetiva en cláusulas de relativo restrictiva (Desapareció la cartera conteniendo el dinero); infinitivos en subordinadas de finalidad con sujeto discrepante (El motivo de la conferencia de prensa es para la compañia desmentir los falsos rumores); infinitivos con sujeto pronominal antepuesto (Yo no me acuerdo de yo ser mala), entre otros (López Morales 1992: 155).

1. “(...) interferencia o transferencia son nociones que hablan de la influencia de una lengua (A) sobre otra (B), produciendo en esta última estructuras agramaticales” (López Morales 1992: 155). 
Este interés por la relación entre el español y el inglés ha sido también la principal causa de que los estudios sobre actitudes lingüísticas en Puerto Rico hayan estado dirigidos, en su mayoría, al bilingüismo. No obstante, se localizan investigaciones relacionadas con la valoración social de determinados fenómenos fonológicos, como es el caso del de la /r/ velarizada (López Morales 1979a; Emmanuelli 1986, 2000) y la inseguridad lingüística (López Morales 1979b).

Alvar (1982) fue uno de los pioneros en el acercamiento al tema y combinó el interés por el estudio de las actitudes hacia el bilingüismo y hacia la modalidad propia en la realidad puertorriqueña. En su investigación no solo indagó por las preferencias de los puertorriqueños sobre el uso del inglés, sino también por la denominación de la lengua que hablan y las actitudes hacia el propio modo de hablar. Algunos de sus principales resultados acerca del orgullo y lealtad lingüística de los puertorriqueños hacia su modalidad han sido corroborados más recientemente en el estudio llevado a cabo en San Juan como parte del proyecto panhispánico LIAS² (Mojica 2014).

Sobre las percepciones dialectales de los puertorriqueños apenas se localizan unas pocas investigaciones. En general, el tema no ha sido muy desarrollado en el mundo hispanohablante (Quesada 2014; Moreno 2015) y la mayoría de los trabajos perceptuales realizados se enfocan en las variedades nacionales, como por ejemplo de Cuba (Sobrino 2013), Costa Rica (Quesada 2013), México (Serrano 2002; Erdösova 2011) y España (Moreno y Moreno 2002). Específicamente sobre Puerto Rico ha sido estudiada comparativamente la percepción de puertorriqueños y mexicanos en relación con algunos fenómenos fonéticos (el fonema nasal dental $/ \mathrm{r}$ /, percusivo $/ \mathrm{r} / \mathrm{y}$ fricativo alveolar /s/ en posición final) (Boomershine 2006) y en el estudio de Mojica (2014), aunque centrado en las actitudes lingüísticas, se incluyen algunas cuestiones relacionadas con el tema.

De este modo, el presente trabajo se propone contribuir a los estudios actitudinales y perceptuales sobre el español puertorriqueño, vinculando los presupuestos teóricos planteados desde la dialectología perceptual y las actitudes lingüísticas, en tanto disciplinas encargadas del estudio de las percepciones, creencias, valoraciones y actitudes de los hablantes comunes sobre la lengua. Los datos que serán analizados forman parte de una investigación mayor sobre

2. Proyecto Linguistic Identity and Attitudes in Spanish-speaking Latin America, dirigido por la Universidad de Bergen, Noruega, y desarrollado durante los años 2009 a 2012. 
las Antillas hispanohablantes ${ }^{3}$ pero en este caso se han seleccionado los resultados obtenidos en Puerto Rico; específicamente, aquellos relacionados con el modo en que perciben su variedad de lengua los hablantes puertorriqueños en el contexto hispanohablante, qué rasgos consideran característicos de su variedad y qué actitudes manifiestan hacia ella.

\section{Marco teórico}

\subsection{Percepciones dialectales}

Las percepciones dialectales de los hablantes han devenido objeto de estudio de la dialectología perceptual, disciplina lingüística que se considera una subrama de la lingüística popular (folk linguistics). Sus propósitos fundamentales se dirigen al trazado de una cartografía lingüística, a semejanza de la dialectología tradicional, pero con base en la percepción dialectal de los hablantes, en las creencias que almacenan en su conciencia lingüística. A diferencia de la geografía lingüística que construye sus mapas a través del análisis de datos lingüísticos recogidos en el terreno, en este caso se trata de mapas mentales construidos por los hablantes comunes en los que trazan límites o isoglosas según sus percepciones y la construcción de estereotipos.

La percepción lingüística y la consecuente interpretación de esas percepciones que el hablante experimenta, manifiestas a través de opiniones, son concebidas del siguiente modo:

La percepción lingüística es básicamente la capacidad de recibir impresiones o sensaciones procedentes del uso de las lenguas. Por su parte, la opinión lingüística puede definirse como la interpretación que los hablantes hacen del posicionamiento social y geográfico de las lenguas. Percepción y opinión son, pues, conceptos traslapados en los que tan importante es el acceso a la realidad lingüística y su consecuente percepción física, como el procesamiento cognitivo e intelectual que los hablantes hacen de las sensaciones experimentadas (Moreno 2015: 217).

Dado que el propósito último de la dialectología perceptual es la representación en mapas de las percepciones de los hablantes, la metodología empleada con más frecuencia parte de presentar al informante un mapa del área de interés, generalmente en blanco, para que el hablante represente en él las diferentes zonas

3. Se trata de la tesis doctoral Actitudes lingüisticas en el Caribe insular hispánico (Sobrino 2017). 
que percibe según la manera de hablar. Además de estas, se han empleado otras técnicas tales como escalas de diferenciación (para establecer el grado de percepción en cuanto a la diferencia de otros dialectos con el propio), identificación de dialectos (a través de grabaciones de variedades dialectales que el informante debe identificar y ubicar en un mapa) y datos cualitativos (entrevistas y preguntas abiertas) (Preston 1999a: xxxiv).

Las investigaciones en este campo han enunciado algunos principios de gran utilidad para el análisis de las percepciones que sobre las variedades dialectales manifiestan los hablantes. Es el caso del principio o efecto de proximidad (Montgomery 2012: 640), el cual plantea que los hablantes tienden a considerar las áreas cercanas con mayor facilidad que otras áreas. No obstante, la proximidad no debe ser entendida solamente como espacio geográfico. Se da el caso de que los hablantes toman en consideración variedades de lengua geográficamente distantes a la suya y aquí entran en juego factores sociales que incrementan el efecto de proximidad, tales como los medios de difusión y las redes sociales. El impacto de la proximidad puede ser modificado por la relativa importancia cultural de un área, ya sea estigmatizada o prestigiosa, es decir, el efecto de la importancia cultural incrementará la proximidad de un área a los informantes y, por tanto, aumentará sus posibilidades de ser incluida en sus mapas mentales (Montgomery 2012: 662).

\subsection{Actitudes lingüisticas}

La actitud lingüística se define como "una manifestación de la actitud social de los individuos, distinguida por centrarse y referirse específicamente tanto a la lengua como al uso que de ella se hace en sociedad" (Moreno 2005: 177). Desde una perspectiva mentalista, como es la predominante en los estudios sobre actitudes, la actitud es un estado mental, una predisposición, una variable que predispone a una persona a reaccionar de una forma $\mathrm{u}$ otra ante un estímulo (Cooper y Fishman 1974). Según esta postura, poseen una estructura multicomponencial, integrada por los componentes cognitivo (conocimiento y creencias del individuo), afectivo (sentimientos, valoración afectiva, identidad) y conativo (actuación o comportamiento) (Lambert 1964).

En el componente cognitivo de las actitudes lingüísticas quedan incluidos los conocimientos y las creencias sobre la lengua. Por ello, la conciencia sociolingüística, es decir, el saber del hablante acerca de las diferentes posibilidades lingüísticas que posee y su capacidad de elección sobre determinadas cuestiones de preferencias 
de uso sociales, condiciona en gran medida las actitudes hacia la lengua (Moreno 2005: 180). Asimismo, la cognición del hablante no está constituida simplemente por el dominio de los rasgos que conforman el sistema, sino que está permeado por su subjetividad, por el modo en que percibe el fenómeno lingüístico o la variante de lengua en cuestión. Por tanto, se habla de una "supuesta cognición" (Blas 1999: 50), las creencias pueden o no estar basadas en la realidad, pero en gran medida no están motivadas empíricamente.

Las actitudes hacia la lengua pueden ser positivas o negativas (López Morales 2004: 291). De este modo, se puede hablar de determinados parámetros, entre los que se encuentran el prejuicio, el estigma, la deslealtad o el rechazo, como actitudes negativas; y la lealtad, la fidelidad, el orgullo, el prestigio o la utilidad, como positivas (Blas 2005: 352).

En trabajos de dialectología perceptual se ha manifestado en forma de reclamo la falta de atención de los estudios actitudinales a la utilidad de los resultados de los estudios perceptuales:

los estudios 'clásicos' sobre actitudes lingüísticas no prestan atención a la conciencia lingüística popular de los encuestados (ni a las estrategias de identificación que utilizan para 'localizar' a los hablantes ni a los 'mapas mentales' que tienen sobre las áreas de habla regional) (Preston 1999b: 129).

En tal sentido, el presente estudio se propone vincular los resultados desde uno y otro ámbito para ofrecer un panorama general que relacione el modo en que los puertorriqueños conciben su variedad de español desde una perspectiva dialectal y las opiniones, valoraciones y reacciones que manifiestan en relación con el español puertorriqueño. Desde el punto de vista teórico, la vinculación de ambas disciplinas, actitudes lingüísticas y dialectología perceptual, puede establecerse no solamente a partir del tipo de dato empírico con el que ambas trabajan, sino también con el hecho de que el objeto de estudio de la dialectología perceptual puede situarse en el componente cognitivo de las actitudes. Por tanto, indagar sobre la percepción dialectal de los hablantes en una investigación sobre actitudes lingüísticas es profundizar en uno de los elementos que las motivan.

\section{Metodología}

Desde el punto de vista metodológico se trabajó con un cuestionario aplicado durante los primeros meses de 2015 en un sector del Área Metropolitana 
de Puerto Rico. Los informantes que formaron parte del estudio residían en el municipio capital de San Juan o algunos de los colindantes, entre los que se encuentran: Bayamón, Guaynabo, Trujillo Alto y Carolina ${ }^{4}$.

La muestra seleccionada se conformó a partir de un muestreo de estratificación uniforme, en el que se asignaron tres informantes por celda, tomando en consideración las variables sexo, edad y nivel de instrucción ${ }^{5}$, para un total de 54 informantes. Como condición inicial para integrar la muestra, el informante debía tener más de 20 años y ser oriundo o haber vivido la mayor parte de su vida en la zona capitalina (como mínimo el $85 \%$ de su vida). La decisión sobre la edad mínima de los informantes está en relación con el hecho de que se considera que, a esta edad, aproximadamente, se ha acumulado una experiencia de vida o se ha transitado ya por varios niveles educativos que permite tener una opinión formada sobre el tema que se aborda.

La variable edad se estructuró a partir de tres grupos etarios:

- $\quad$ primer grupo etario (IGE): 20 a 34 años

- $\quad$ segundo grupo etario (IIGE): 35 a 54 años

- $\quad$ tercer grupo etario (IIIGE): 55 años o más

Los niveles de instrucción se determinaron del siguiente modo:

- Nivel bajo (NB): noveno grado de estudios como máximo alcanzado

- Nivel medio (NM): duodécimo grado o educación técnica como máximo alcanzado

- Nivel alto (NA): estudios universitarios concluidos

El cuestionario aplicado contó con once preguntas relacionadas temáticamente con las percepciones dialectales y las actitudes lingüísticas, ya fuera hacia

4. En general, la población de los cinco municipios se acerca al millón de habitantes (952.970). La información estadística de Puerto Rico fue tomada de los datos del censo de 2010 publicados en http:// factfinder.census.gov/faces/tableservices/jsf/pages/productview.xhtml?src=bkmk. La población de cada uno de los municipios es la siguiente: San Juan 395 326, Guaynabo 97 924, Bayamón 208.116, Trujillo Alto 74.842 y Carolina 176.762 .

5. A pesar de que tradicionalmente los estudios sociolingüísticos en Puerto Rico han tomado en consideración la variable clase social, en este caso, debido al carácter comparativo que tuvo la investigación de la que se han tomado estos resultados, se consideró el nivel de instrucción como variable social que permitiera comparar las realidades de los tres países estudiados (Cuba, Puerto Rico y República Dominicana). 
el español nacional o hacia otras variedades antillanas (Ver Apéndice). De ellas, han sido seleccionadas ocho preguntas (preguntas de 1 a 7 y pregunta 11) cuyas respuestas permiten profundizar en el modo en que los puertorriqueños perciben su variedad de lengua en relación con el resto de las variedades hispánicas, los rasgos a través de los cuales la identifican y las actitudes que manifiestan hacia ella.

Las preguntas en cuestión son preguntas abiertas y una escala Likert. Con las preguntas abiertas se ha pretendido obtener el mayor volumen de información posible y ha permitido que el informante exprese libremente sus criterios, sin ceñirse a respuestas previamente concebidas. Por su parte, la escala Likert, recurso muy usual en los estudios sobre actitudes lingüísticas, ha permitido constatar las reacciones de los informantes hacia determinados aspectos relacionados con el español puertorriqueño.

\section{Presentación de resultados}

\subsection{Percepción de similitudes y diferencias entre variedades}

Sobre las percepciones dialectales de los hablantes puertorriqueños el cuestionario incluyó seis preguntas dirigidas específicamente a conocer qué variedades de español consideran similares y diferentes a la propia, en qué criterios basan esas consideraciones y cuáles son las causas que asocian a la existencia de tales semejanzas o diferencias. Las preguntas realizadas fueron las siguientes:

1. Mencione otros países donde hablan el español de modo similar a como se habla aquí

2. ¿En qué consisten esas semejanzas?

3. ¿Cuáles cree usted que sean las causas de que existan estas semejanzas?

4. Mencione otros países donde hablan el español de modo diferente a como se habla aquí

5. ¿En qué consisten esas diferencias?

6. ¿Cuáles cree usted que sean las causas de que existan estas diferencias?

Las respuestas ofrecidas a las preguntas 1 y 4 han sido representadas en mapas en los que el país estudiado aparece representado en color negro y las respuestas aparecen en color azul, en el mapa que representa las semejanzas, y en color rojo, en el que ilustra las diferencias. En estas preguntas no se estableció 
un límite de países, los informantes tenían total libertad para mencionar los que entendieran pertinentes en la respuesta. En cuanto a las cuatro preguntas restantes $(2,3,5$ y 6$)$, las respuestas fueron codificadas a posteriori y se sistematizaron en criterios que facilitaran el análisis.

Con excepción de algunos pocos, la mayoría de los países hispanohablantes fueron mencionados por los puertorriqueños cuando se trataba de considerar variedades semejantes. No obstante, en el Mapa 1 solo se han representado aquellos con porcentajes significativos, por encima de la media del total de menciones. De este modo, queda representado que para los puertorriqueños son los cubanos, en primer lugar, seguidos de dominicanos y venezolanos, los más similares a ellos en cuanto al modo de hablar, y quedan ubicados en lugares sucesivos panameños y colombianos. En general, ellos conciben su variedad circunscrita a un área dialectal similar a la descrita desde la dialectología tradicional (Quesada

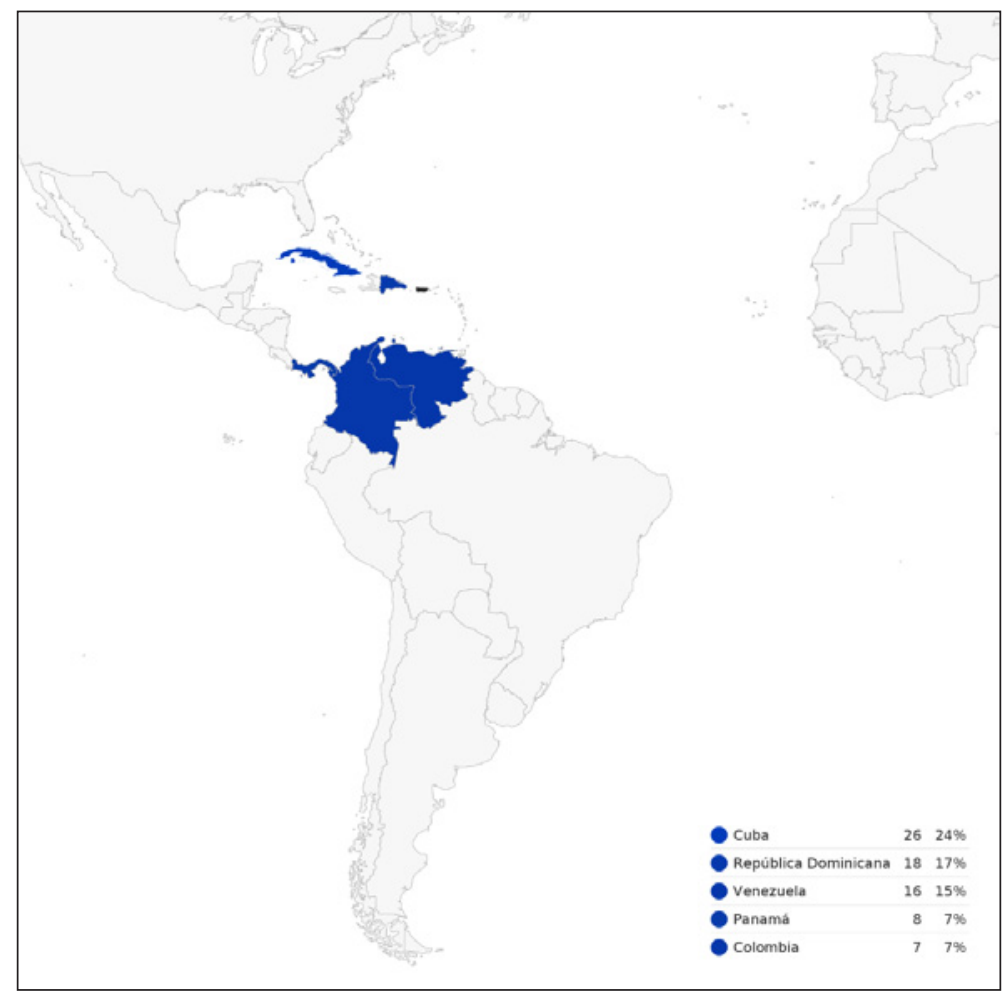

Mapa 1. Lugares percibidos como semejantes lingüisticamente por los puertorriqueños 
2010), con límites continentales que se extienden hasta Panamá y Colombia, lo cual evidencia el cumplimiento del principio de proximidad según el cual lo más cercano es lo que forma parte de los mapas mentales de los hablantes.

Aunque las unidades de percepción pensadas para el análisis se ajustaban a países; es decir, a territorios nacionales hispanohablantes, en algunos casos se hizo mención de regiones de España como Islas Canarias y Andalucía. Algo similar sucede con Estados Unidos, de este país se mencionó la ciudad de Orlando y el estado de la Florida, donde radican comunidades numerosas de puertorriqueños.

Los tipos de respuestas ofrecidas según el número de variedades a considerar también apuntan a la percepción de los puertorriqueños de un área dialectal reducida, circunscrita a la zona caribeña. El 33,2\% de los informantes dieron respuestas que se han calificado como monoperceptuales, es decir, que tienen en cuenta una sola variedad de español, y la misma cantidad $(33,2 \%)$ ofrecieron respuestas biperceptuales. En los casos en que mencionaron solo una se trató de la variedad cubana o dominicana, y los que relacionaron dos vincularon estas o las de Cuba y Venezuela.

En cuanto a las similitudes entre las variedades, los puertorriqueños expusieron argumentos relacionados fundamentalmente con el vocabulario, elementos suprasegmentales y fonéticos, entre otros de tipo lingüístico (ver Tabla 1). Asimismo, se hizo referencia en menor medida a cuestiones de comunidad cultural y a rasgos identitarios comunes entre los países mencionados.

Tabla 1. Criterios para el establecimiento de semejanzas lingüisticas

\begin{tabular}{|c|c|c|c|}
\hline \multicolumn{2}{|r|}{ Criterios } & No. de menciones & $\%$ \\
\hline \multirow{11}{*}{ 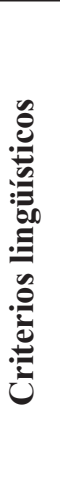 } & nivel léxico & 21 & 27,6 \\
\hline & nivel suprasegmental & 12 & 15,8 \\
\hline & nivel fónico & 9 & 11,8 \\
\hline & lengua común & 2 & 2,6 \\
\hline & espanglish & 1 & 1,3 \\
\hline & nivel sintáctico & 1 & 1,3 \\
\hline & forma de expresión & 4 & 5,3 \\
\hline & incorrección & 1 & 1,3 \\
\hline & comprensión & 3 & 3,9 \\
\hline & rapidez elocutiva & 2 & 2,6 \\
\hline & Subtotal & 56 & 73,7 \\
\hline
\end{tabular}




\begin{tabular}{|c|c|c|c|}
\hline \multirow{4}{*}{ 赵 } & cultura & 8 & 10,5 \\
\hline & identidad & 1 & 1,3 \\
\hline & cercanía geográfica & 1 & 1,3 \\
\hline & Subtotal & 10 & 13,2 \\
\hline \multirow{5}{*}{$\stackrel{\mathscr{E}}{0}$} & no responde & 2 & 2,6 \\
\hline & no sé & 5 & 6,6 \\
\hline & otra & 3 & 3,9 \\
\hline & Subtotal & 10 & 13,2 \\
\hline & Total de menciones & 76 & 100 \\
\hline
\end{tabular}

Algunos ejemplos de los criterios aportados son:

- Cuba: (I-9) ${ }^{6}$ nos parecemos en el vocabulario y la entonación; (I-13) hablamos rápido; (I-19) frases y tono al hablar.

- República Dominicana: (I-16) las semejanzas son que no hablamos el español correctamente, cometemos muchos errores, por ejemplo, cambiamos la erre por la ele, también se parece en el acento; (I-25) en la forma de expresarse, los nombres de las cosas; (I-38) por ser caribeños.

- Andalucía: (I-5) de los colonizadores provenientes de esa región los puertorriqueños utilizamos el apócope de ciertas palabras como pa por para, to por todo, entre otros; el intercambio de la erre por ele; se comen las eses.

- Islas Canarias: (I-10) modo de hablar y palabras similares.

- Cuba y República Dominicana: (I-3) consisten en la rapidez; (I-8) vivimos en la zona caribeña y nuestra forma de hablar es un poco similar; (I-32) algunas palabras, tonos y acento, expresiones; (I-37) el español es similar, lo que cambia es el acento o palabras con diferente significado.

- Cuba, República Dominicana, Colombia, Panamá, Costa Rica, México, Perú, Chile, Argentina, Uruguay, Paraguay: (I-12) solo existen regionalismos para ciertas palabras y el acento cambia, pero lo demás es igual.

6. Esta numeración se corresponde con el etiquetado del corpus: I (informante) -X (número del informante). 
En la Tabla 2 se registran las frecuencias absolutas y relativas de los criterios en los que se agruparon las explicaciones ofrecidas por los informantes sobre las causas de las similitudes lingüísticas entre estos países. La cercanía geográfica fue uno de los aspectos más tomados en consideración, aunque también tomaron en cuenta criterios relacionados con el proceso de colonización, la cultura, los orígenes étnicos, las migraciones. Es destacable que un 24,7\% de los informantes no respondió, dijo no saber o no aportó ninguna información en su respuesta, lo que evidencia cierto desconocimiento del tema.

Tabla 2. Causas de semejanzas lingüisticas

\begin{tabular}{|c|c|c|c|}
\hline \multicolumn{2}{|r|}{ Criterios } & No. de menciones & $\%$ \\
\hline \multirow{3}{*}{ 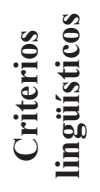 } & lengua común & 2 & 2,7 \\
\hline & nivel léxico & 1 & 1,4 \\
\hline & Subtotales & 3 & 4,1 \\
\hline \multirow{8}{*}{ U } & colonización & 6 & 8,2 \\
\hline & identidad & 2 & 2,7 \\
\hline & cercanía geográfica & 15 & 20,5 \\
\hline & cultura & 9 & 12,3 \\
\hline & orígenes étnicos & 10 & 13,7 \\
\hline & migraciones & 9 & 12,3 \\
\hline & cercanía a Estados Unidos & 1 & 1,4 \\
\hline & Subtotales & 52 & 71,2 \\
\hline \multirow{4}{*}{$\stackrel{\mathscr{t}}{0}$} & no responde & 5 & 6,8 \\
\hline & no sé & 11 & 15,1 \\
\hline & otras & 2 & 2,7 \\
\hline & Subtotales & 18 & $\mathbf{2 4 , 7}$ \\
\hline & Total de menciones & 73 & 100 \\
\hline
\end{tabular}

Algunas de las explicaciones fueron:

- Cuba: (I-4) la emigración de cubanos a Puerto Rico; (I-11) cultura, herencia; (I-13) acercamientos históricos; (I-19) base española.

- República Dominicana: (I-16) existen estas semejanzas porque somos paises vecinos; (I-8) somos caribeños; (I-25) tenemos las mismas costumbres. 
- Venezuela: (I-47) estamos cerquita, en el juego de pelota tenemos muchas palabras parecidas.

- Andalucía: (I-5) estas semejanzas se deben a que la mayoría del país fue colonizado por residentes de dicha región andaluza; (I-40) las migraciones del sur de España.

- Islas Canarias: (I-10) mayor influencia de canarios en el Caribe que de la península.

- Cuba, República Dominicana, Venezuela, Panamá: (I-14) por la influencia española, africana, por nuestra música, por el calor.

- Cuba, Colombia, Ecuador, Perú: (I-34) tiene que ver con la colonización y las migraciones, por ejemplo, en Panamá hay muchos de Puerto Rico.

En cuanto a la consideración de variedades hispánicas diferentes a la propia, los puertorriqueños mencionaron con mayor frecuencia las de Argentina, España y México (Mapa 2). También se refirieron al área centroamericana y a regiones españolas, como Cataluña y el País Vasco, y es notable el área que se extiende desde Colombia hasta Argentina, reconocida casi en su totalidad como marcadamente diferente.

Es de destacar que entre las variedades más percibidas como diferentes aparecen algunas que, a su vez, integran el mapa perceptual de semejanzas de los puertorriqueños (Mapa 1), como por ejemplo la colombiana y la dominicana; esta última con una frecuencia de mención mayor que otros países lejanos $(5 \%)$. Sobre Colombia puede argumentarse que esta variedad se encuentra en el límite de la zona que los puertorriqueños distinguen como propia, por lo que resulta comprensible que exista variación sobre el modo en el que es percibida, además de que los rasgos que los informantes pueden tomar en consideración pueden ubicarla como semejante o diferente, según se trate de la variedad costera o la del interior del país.

En relación con República Dominicana entran en juego otros factores. Las opiniones para señalar diferencias con respecto al español dominicano llevan implícitas cierta discriminación hacia esta variedad, condicionada por la imagen que se tiene del dominicano en Puerto Rico, vinculada, a su vez, al complicado contexto migratorio que envuelve a estos países vecinos (Sobrino 2017). Los dominicanos en Puerto Rico constituyen la comunidad de inmigrantes más numerosa y, en su mayoría, se dedican a trabajar en la construcción, la agricul- 


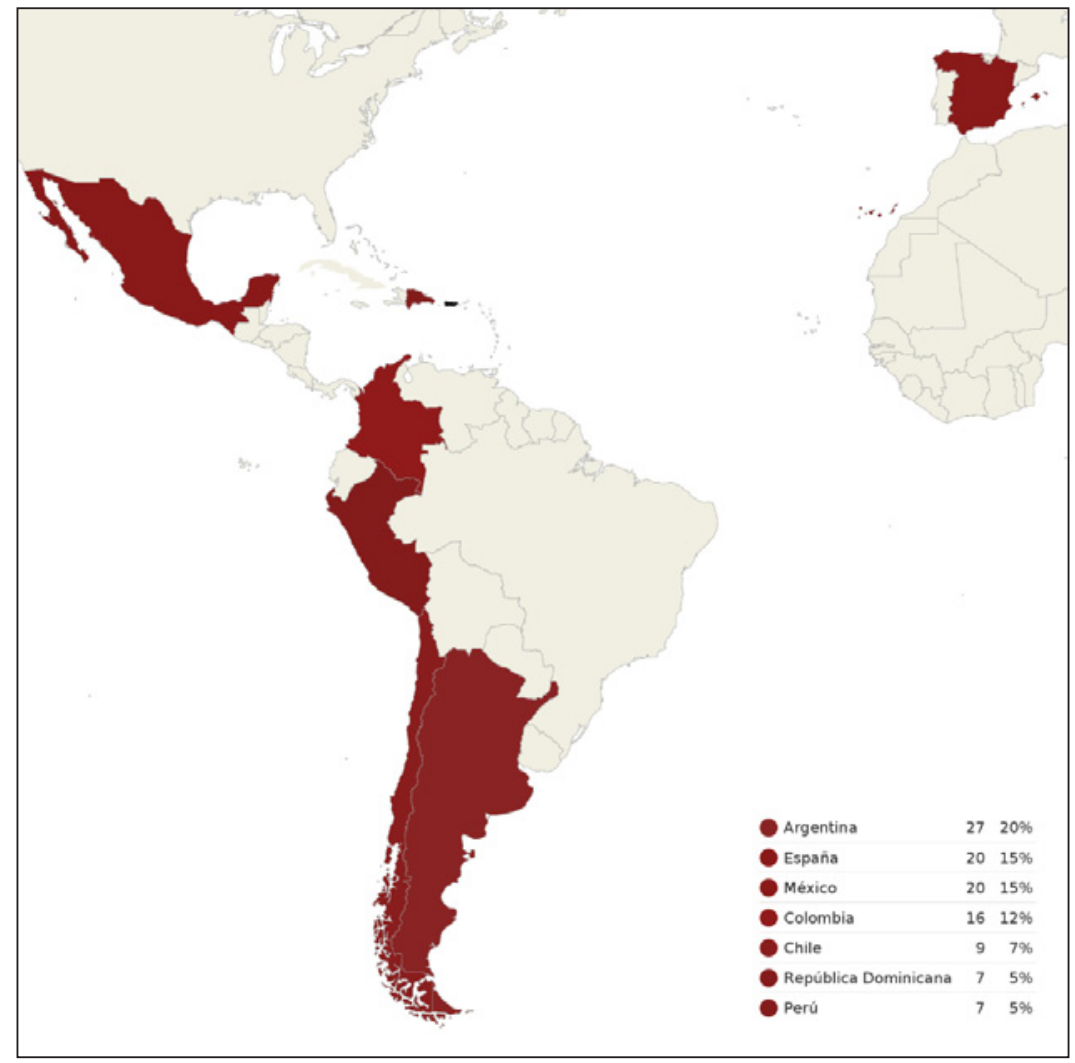

Mapa 2. Lugares percibidos como diferentes lingüísticamente por los puertorriqueños

tura, los servicios domésticos. El estereotipo dominicano es objeto de caricaturización y discriminación social, al punto de que se ha llegado a asociar con ilegalidad, negritud y se les acusa de estar "invadiendo" la isla puertorriqueña (Montijo 2005-2006) ${ }^{7}$.

Todo ello, unido a las motivaciones de la migración y las vías de acceso, ha contribuido a la construcción de un estereotipo de hablante dominicano que

7. Al respecto, la presidenta electa del Colegio Dominicano de Periodistas, Gheidy De la Cruz, expresó: "La comunidad dominicana en Puerto Rico no escapa a las prácticas de discrimen y vulneración de sus derechos civiles. Además de ser objeto de estereotipos a partir de los cuales se presenta una imagen caricaturesca del inmigrante dominicano, que resta méritos a sus capacidades y lo categoriza como un ciudadano de menor nivel". http://acento.com.do/2011/actualidad/8143-dominicanos-residentes-enpuerto-rico-denuncian-discriminacion-y-maltrato/. 
es fuertemente discriminado por el puertorriqueño y conlleva a que una variedad tan cercana geográficamente, con la que los informantes comparten usos lingüísticos, destaque en el mapa perceptual de diferencias. Tanto es así, que estudios fonéticos sobre la oclusión glotal de /s/ en Puerto Rico han interpretado esta realización como una práctica de afirmación lingüística de la identidad puertorriqueña frente a la inmigración dominicana: "la adopción de una nueva variante en el repertorio insular ofrece más posibilidades para evitar la elisión, altamente estigmatizada por asociarse con el bajo nivel socioeconómico de muchos inmigrantes indocumentados que vienen de ese país" (ValentínMárquez 2006: 340).

En las ideas aportadas se reiteró la influencia de lenguas indígenas en algunas variedades suramericanas y la cercanía de algunas variantes al ideal de corrección, como es el caso de España, Argentina, Colombia, que permiten diferenciarlas de la propia. Entre las diferencias que explican los puertorriqueños están:

- España: (I-12) demasiados términos coloquiales que no se asemejan; (I-45) el acento es diferente, pronuncian diferentes algunas palabras; (I-16) viví en Madrid y puedo comparar mi español con el de un madrileño, ellos son muy cuidadosos y correctos con el idioma; (I-51) los de España usan la zeta todo el tiempo.

- Argentina: (I-51) siempre suenan raros con el cha, cho quiero.

- México: (I-18) tienen un acento bien fuerte, les gusta sonar mucho la erre; (I-52) se creen que son más altaneros.

- República Dominicana: (I-47) hablan raro, tienen un cantao y usan mucho la i. Se parecen a los de Lares en Puerto Rico que usan mucho la i; (I-44) hablan feo, dicen haiga, puieta, papei; (I-23) hablan cantado en Santo Domingo.

- Argentina, Colombia, Costa Rica: (I-38) entiendo que su español es más correcto que aquí.

- Chile, Perú: (I-40) no se comen las letras, hablan más europeo.

- Colombia, Argentina: (I-22) como se expresan, son más educados.

- Perú, Colombia, Argentina: (I-46) tienen influencias indígenas. 
La Tabla 3 ilustra el comportamiento cuantitativo de los criterios en los que se agruparon los argumentos para señalar diferencias entre variedades. En los aspectos mencionados destacan igualmente rasgos correspondientes a los niveles suprasegmentales, léxico y fónico como los que con mayor frecuencia toman en consideración los hablantes para argumentar sus percepciones. En mucha menor medida se hace referencia a elementos extralingüísticos.

Tabla 3. Criterios para el establecimiento de diferencias lingüisticas

\begin{tabular}{|c|c|c|c|}
\hline \multicolumn{2}{|r|}{ Criterios } & No. de menciones & $\%$ \\
\hline \multirow{9}{*}{ 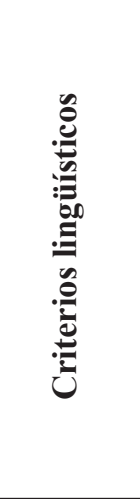 } & nivel léxico & 20 & 26,0 \\
\hline & nivel suprasegmental & 29 & 37,7 \\
\hline & nivel fónico & 10 & 13,0 \\
\hline & influencia de otras lenguas & 3 & 3,9 \\
\hline & formas de tratamiento & 2 & 2,6 \\
\hline & forma de hablar & 1 & 1,3 \\
\hline & corrección & 2 & 2,6 \\
\hline & rapidez elocutiva & 1 & 1,3 \\
\hline & Subtotales & 68 & 88,3 \\
\hline \multirow{5}{*}{ : } & cultura & 1 & 1,3 \\
\hline & origen étnico & 1 & 1,3 \\
\hline & ubicación geográfica & 1 & 1,3 \\
\hline & migraciones & 2 & 2,6 \\
\hline & Subtotales & 5 & 6,5 \\
\hline \multirow{5}{*}{$\stackrel{\mathscr{0}}{0}$} & no responde & 1 & 1,3 \\
\hline & no sé & 1 & 1,3 \\
\hline & otra & 2 & 2,6 \\
\hline & Subtotales & 4 & 5,2 \\
\hline & Total de menciones & 77 & 100 \\
\hline
\end{tabular}

Sobre las causas que han originado estas diferencias dialectales los puertorriqueños declararon aspectos concernientes a la diversidad étnica, las diferencias culturales y la distancia geográfica, fundamentalmente (ver Tabla 4): 
Tabla 4. Causas de diferencias lingüísticas

\begin{tabular}{|c|c|c|c|}
\hline & Criterios & No. de menciones & $\%$ \\
\hline \multirow{4}{*}{ 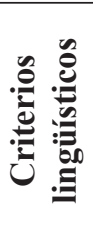 } & variación dialectal & 3 & 4,3 \\
\hline & corrección & 1 & 1,4 \\
\hline & incomprensión & 2 & 2,9 \\
\hline & Subtotal & 6 & 8,7 \\
\hline \multirow{8}{*}{ U. } & colonización & 2 & 2,9 \\
\hline & ubicación geográfica & 11 & 15,9 \\
\hline & cultura & 11 & 15,9 \\
\hline & orígenes étnicos & 16 & 23,2 \\
\hline & migraciones & 2 & 2,9 \\
\hline & nivel cultural & 4 & 5,8 \\
\hline & influencia de Estados Unidos & 1 & 1,4 \\
\hline & Subtotal & 47 & 68,1 \\
\hline \multirow{5}{*}{$\stackrel{\mathscr{0}}{0}$} & no responde & 1 & 1,4 \\
\hline & no sé & 11 & 15,9 \\
\hline & otras & 4 & 5,8 \\
\hline & Subtotal & 16 & 23,2 \\
\hline & Total de menciones & 69 & 100 \\
\hline
\end{tabular}

Los ejemplos aportados al respecto fueron:

- Argentina: (I-3) creo que los argentinos tienen influencia italiana y nosotros de Estados Unidos.

- Paraguay, Uruguay, Argentina, Venezuela: (I-7) me imagino que por nuestro trasfondo de los españoles, africanos y tainos que no han tenido esos otros países.

- México, Argentina, Colombia: (I-20) son países más grandes y con diferentes influencias.

- Chile, Argentina: (I-24) son de Suramérica.

- España: (I-33) está en otro continente. 
- República Dominicana: (I-44) no tienen escolaridad, muchos no pueden ir a la escuela; (I-47) no tienen educación.

Si se comparan las creencias relacionadas con las causas de las semejanzas y las diferencias lingüísticas entre el español propio y el resto de las variedades, debe resaltarse que, aunque se contemplan en general los mismos criterios, la cercanía geográfica entre territorios y la influencia del proceso de colonización como hecho histórico se relacionan más estrechamente como causante de que las variedades de lengua se asemejen; mientras que los orígenes étnicos de los grupos conformadores de las naciones y sus rasgos culturales caracterizadores, entendidos quizás como el resultado de ese proceso histórico, se conciben con más frecuencia como causas de diferencias lingüísticas.

En las variables sociolingüísticas estudiadas, específicamente en la variable sexo, las mujeres destacan por sobre los hombres en la consideración de criterios lingüísticos para establecer las semejanzas entre variedades (44,6\% sobre $28,9 \%$ ). En ello sobresalen especialmente las mujeres más jóvenes (IGE), pues son las únicas en tomar en consideración criterios como la rapidez elocutiva, el uso del espanglish y la incorrección. Lo mismo sucede con el establecimiento de las diferencias, es el sexo femenino el que menciona argumentos relacionados con las formas de tratamiento, el nivel cultural y los orígenes étnicos como marcadores de diferenciación entre las variantes.

En cuanto a las causas de las semejanzas se sigue la misma tendencia de comportamiento. Las mujeres aportan más opiniones (41,1\% sobre $30,1 \%)$, mientras que los hombres tienden más que ellas a manifestar desconocimiento. En las causas de las diferencias esta variable no presentó variación significativa.

La variable edad no arrojó prácticamente resultados destacables. Por niveles de instrucción, de los datos se deduce que el desconocimiento es mayor mientras menor es el nivel educacional de los informantes, los del NB son los que más declaran no saber. Al mismo tiempo, a medida que aumenta la instrucción aumenta también la consideración de los niveles lingüísticos para establecer las semejanzas (léxico, fónico, suprasegmental).

\subsection{Caracterización de la variedad puertorriqueña}

Para profundizar en el componente cognitivo de las actitudes lingüísticas se les pidió a los informantes caracterizar su forma de hablar a partir de aquellos 
rasgos que consideraran más significativos de su modalidad de español (pregunta 7: ¿Qué características cree usted que permiten reconocer la forma de hablar de su país?). El propósito fundamental de esta pregunta es analizar cuáles rasgos conforman la conciencia lingüística de los hablantes, según los cuales ellos consideran que pueden ser identificados como nacionales de su país o como hablantes de una modalidad determinada de español, para de este modo reunir datos que complementen sus percepciones y confirmen la valoración positiva o negativa que hacen de su variedad lingüística.

Los rasgos caracterizadores se agruparon en dos grandes grupos: lingüísticos y no lingüísticos. A pesar de describir una variedad de lengua los elementos expuestos no estuvieron ceñidos exclusivamente a lo lingüístico, sino que se hizo una considerable mención de elementos extralingüísticos y de otros que se han dado en llamar «lingüísticos - no verbales» puesto que hacen referencia a un conjunto de características que, si bien están relacionadas con el uso de la lengua, no se ciñen a lo estrictamente verbal.

Los criterios establecidos son:

\section{Lingüísticos}

- Verbales

$\checkmark$ nivel léxico

$\checkmark$ nivel fónico

$\checkmark$ nivel sintáctico

$\checkmark$ nivel suprasegmental

$\checkmark$ corrección

$\checkmark$ anglicismos

$\checkmark$ influencia de otras lenguas

- No verbales

En el Gráfico 1 se ilustra que los puertorriqueños caracterizan su modalidad de lengua basados fundamentalmente en criterios lingüísticos, con un mayor énfasis en los niveles suprasegmental, fónico y léxico, seguidos de aquellos lingüísticos no verbales. También hicieron referencia al uso de anglicismos, el apego a la norma, el nivel sintáctico y la influencia de otras lenguas. Los elementos no lingüísticos estuvieron ceñidos a la mención de rasgos culturales y en algún caso al nivel cultural. 


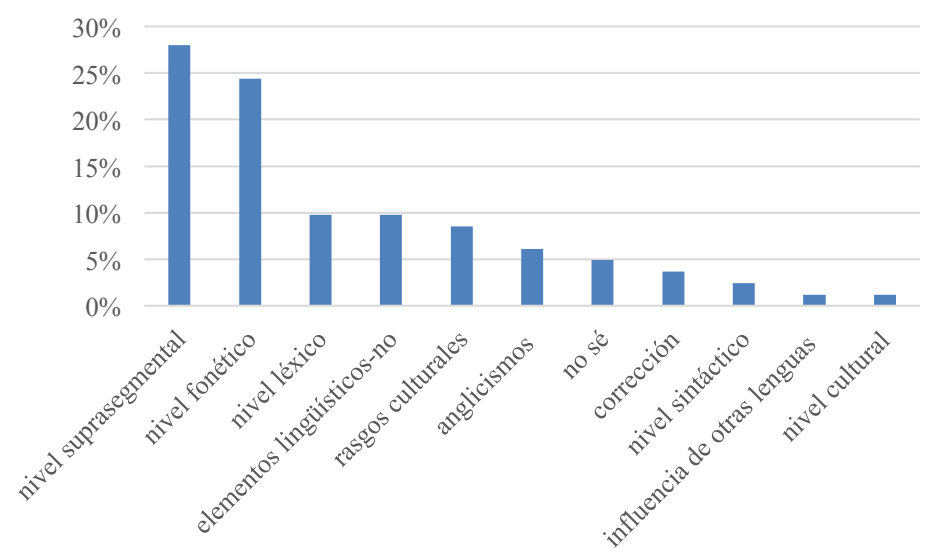

Gráfico 1. Representatividad de los criterios considerados característicos de la variedad puertorriqueña del español

La alusión a elementos correspondientes al nivel suprasegmental se basó casi exclusivamente en la referencia al acento y la entonación y solo en algunos pocos casos añadieron que "cantan" o que "hablamos cantando por el énfasis que le damos a la última sílaba de la palabra o última palabra de cada oración".

Las cuestiones de pronunciación tuvieron un gran peso en la caracterización de los puertorriqueños. Bajo este rubro expusieron ideas tales como: (I-1) tendemos a no pronunciar las eses y pronunciamos las erres como eles; (I-29) aspiración de la /-s/ final y la lateralización de la /r/; (I-4) eliminación de ciertos sonidos; (I-6) el seseo; (I-13) arrastramos la erre.

De todos ellos el rasgo más mencionado fue el que se corresponde con el fenómeno del lambdacismo y que se puede resumir en el siguiente comentario: (I-16) el rasgo principal entiendo que es que cambiamos la letra erre por ele. Por ejemplo, decimos el nombre de nuestro propio país incorrectamente. En vez de decir [pwérto ríko] decimos [pwélto ríko], [kolól] por [kolór], [bélde] por [bérde].

Mención destacada también tuvo el uso de determinados vocablos o refranes característicos del país: marinerismos, palabras taínas y africanas, palabras o expresiones (revolú, mijo, jay bendito!). Asimismo, se toma en consideración, aunque no con alta frecuencia, la influencia del inglés en el español de Puerto Rico, limitada al uso de palabras de esta lengua.

Se manifestaron criterios relacionados con la corrección de esta variante como rasgo distintivo: (I-34) el español de Puerto Rico es más fino, claro, depende del 
sitio del país, porque en el campo no es tan correcto; nos expresamos mejor. Igualmente se hizo referencia a determinados usos gramaticales como (I-31) la preferencia en el uso del modo indicativo en la conjugación de los verbos.

De igual modo, concedieron importancia a esos elementos denominados lingüísticos - no verbales que complementan la comunicación: (hablar) rápido, (hablar) duro, gestualidad (hablar con las manos). También comentaron rasgos culturales y apelaron a adjetivos tales como: bulliciosos, alegres, jibaritos ${ }^{8}$, buenazos, pacíficos, conversadores.

El comportamiento de las variables sociolingüísticas controladas en el estudio arrojó que, por sexos, son las mujeres las que aportan un mayor número de cuestiones en sus argumentaciones (52,6\%). En cuanto a la edad, los grupos etarios más jóvenes (IGE y IIGE) tomaron más en consideración que los mayores lo relacionado a cuestiones lingüísticas para caracterizarse lingüísticamente (el 30,5\% de los criterios aportados por cada uno de estos grupos se relacionó con rasgos lingüísticos, frente al 24,4\% de los del IIIGE). Los del IIIGE priorizan los elementos extralingüísticos, fundamentalmente la mención de rasgos culturales $(6,2 \%$ frente a ninguna respuesta sobre este aspecto por parte de los más jóvenes y 2,4\% del IIGE).

En cuanto al nivel de instrucción los datos confirman que, a mayor nivel educacional, más sensibles se muestran los informantes a referir rasgos correspondientes a los diferentes niveles lingüísticos, fundamentalmente fónico y léxico, para describir sus variantes; los de NA los mencionan con mucha más frecuencia $(39,3 \%)$ que los de NB $(23,8 \%)$.

\subsection{Escala Likert}

La escala Likert o escala de acuerdo consiste en una serie de afirmaciones que expresan opiniones sobre el objeto de actitud y los informantes han de manifestar su reacción al elegir una de las categorías que integran la escala, las cuales van de lo más favorable a lo más desfavorable (Hernández-Campoy y Almeida 2005: 131; Hernández Sampieri et al. 2010: 245).

La escala aplicada se construyó tomando en cuenta cinco categorías: Totalmente de acuerdo (TA), De acuerdo (DA), Ni de acuerdo ni en desacuerdo (I), En desacuerdo (ED) y Totalmente en desacuerdo (TD). Como se muestra en la

\section{8. jíbaro, ra.}

7. adj. Perú, P. Rico y R. Dom. Dicho de una persona: campesino (\| que vive y trabaja en el campo). U. t. c. s. En P. Rico, u. referido especialmente al de ascendencia española. / 8. adj. Perú, P. Rico y R. Dom. campestre. Fiesta jíbara. (RAE 2015). 
Tabla 5, las diez afirmaciones o ítems que conforman la escala Likert fueron agrupadas en subescalas según se refirieran a los siguientes criterios: parámetros actitudinales negativos ( 7 ítems) y parámetros actitudinales positivos $(3)^{9}$, denominados así puesto que el estar de acuerdo con el contenido de estas afirmaciones supondría la manifestación de una actitud negativa o positiva, respectivamente. Los ítems fueron presentados de forma aleatoria (Ver Apéndice); es decir, para su aplicación no se agruparon temáticamente con el propósito de no condicionar una reacción en el informante.

Tabla 5. Criterios en los que se agruparon las afirmaciones de la escala Likert

\begin{tabular}{|c|c|}
\hline Criterios & Ítems \\
\hline \multirow{7}{*}{$\begin{array}{c}\text { Parámetros } \\
\text { actitudinales } \\
\text { negativos }\end{array}$} & 1) Los puertorriqueños pronunciamos muy mal \\
\hline & 2) En mi país se habla con muchas incorrecciones \\
\hline & 3) El español de mi país no se debe enseñar en las escuelas \\
\hline & 4) El español que se habla en las Antillas es el peor español \\
\hline & 5) Cuando hablo con personas de otros países cambio mi manera de hablar \\
\hline & 6) Me trae beneficios no hablar como los de aquí \\
\hline & 7) A las personas de los demás países no les gusta cómo se habla aquí \\
\hline \multirow{3}{*}{$\begin{array}{l}\text { Parámetros } \\
\text { actitudinales } \\
\text { positivos }\end{array}$} & 8) Mi modo de hablar me identifica con los de mi país \\
\hline & 9) Me siento muy orgulloso de mi forma de hablar \\
\hline & 10) Nunca cambiaría mi forma de hablar \\
\hline
\end{tabular}

Para el análisis de los resultados se ha empleado la estadística descriptiva; es decir, los datos de frecuencia relativa de cada opción, el cálculo de la moda, la media y la desviación estándar. Para calcular las medidas de tendencia central (moda y media) y de variabilidad (desviación estándar) se le ha concedido un valor a cada respuesta: $T A=1, D A=2, I=3, E D=4, T D=5$. Con la moda se obtiene la respuesta más frecuente en cada ítem; la media determina el promedio de respuestas y, dado que el valor medio de la escala es 3, se valorará el promedio de respuestas según se ubique por debajo o no de este valor. La desviación estándar proporciona información acerca de la homogeneidad de las respuestas.

9. Para el presente análisis se han tomado en consideración 10 ítems de los 13 que conforman la escala del cuestionario aplicado (Ver Apéndice). Estos fueron los agrupados en los criterios “parámetros actitudinales negativos" y "parámetros actitudinales positivos". 
Las afirmaciones que se han reunido en el criterio «parámetros actitudinales negativos» estuvieron dirigidas a determinar la reacción de los hablantes ante creencias discriminatorias en cuanto a la consideración de la variedad propia como incorrecta o alejada de la norma $(1,2,4)$, su vinculación con la enseñanza (3), la deslealtad (5), la inutilidad (6) y la inferioridad lingüísticas (7).

Los datos presentados en el Gráfico 2 y la estadística descriptiva que ilustra la Tabla 6 en relación con las siete afirmaciones que presuponen actitudes negativas de los puertorriqueños hacia su variedad de español evidencian que, en general, predomina el desacuerdo ante afirmaciones de este tipo o manifiestan una postura intermedia que no se decanta por ninguna de las posiciones extremas.

Ante las afirmaciones 1 y 2 que centran la atención en los rasgos fonéticos y la incorrección, prevalece la postura intermedia (I). La mayoría de los informantes no se decanta por el acuerdo o el desacuerdo, sino que en general tienden a dudar al respecto, pero evidencian una mayor tendencia al desacuerdo. En cambio, en las afirmaciones 3 y 4 que suponen posturas más extremas, los puertorriqueños se inclinan por el total desacuerdo. La respuesta más frecuente se corresponde con $T D$ y se muestra gran homogeneidad en las respuestas, sobre todo en la afirmación relacionada con la vinculación del español propio y la enseñanza de la lengua en las escuelas.

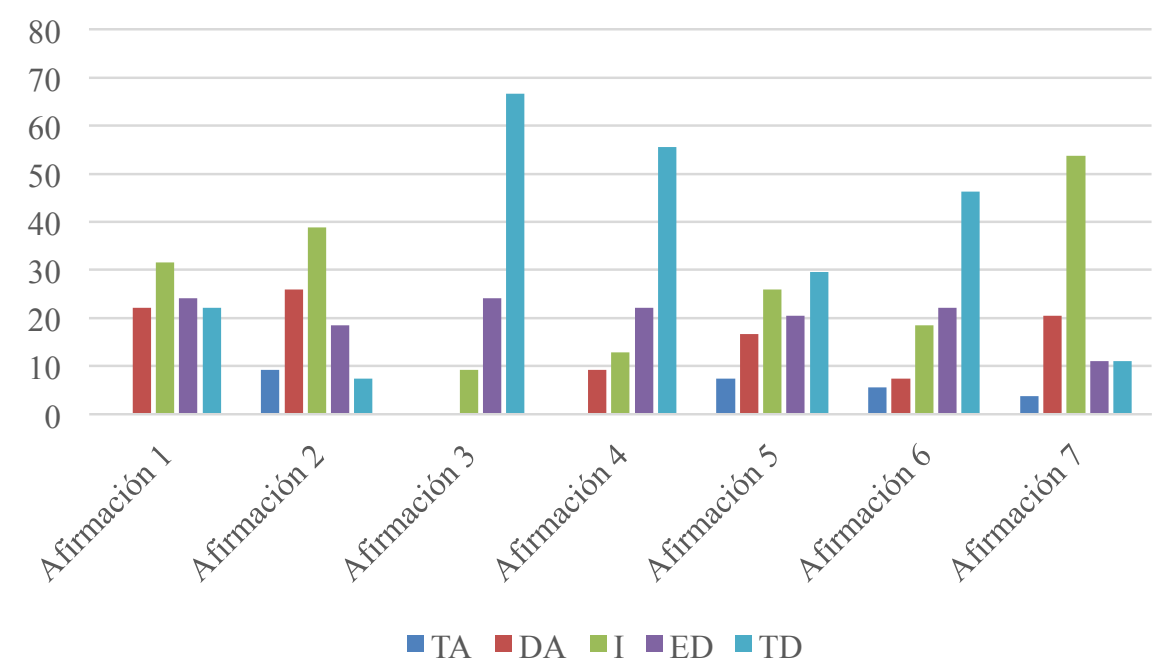

Gráfico 2. Frecuencias relativas de cada opción en parámetros actitudinales negativos 
En lo que respecta a las afirmaciones 5 y 6 , la moda en ambos casos es también 5 , es decir, se tiende a mostrar desacuerdo extremo con estas ideas, pero la desviación estándar muestra una mayor dispersión en las respuestas. Las opciones elegidas en estos casos dan cuenta de la fidelidad y el reconocimiento de la utilidad lingüística de los puertorriqueños. Sin embargo, cuando se trata de valorar la opinión que tiene el resto de su variante dialectal (afirmación 7) los boricuas tienden a mostrarse inseguros (moda 3 ) sobre la aceptación positiva que tiene su variante en el mundo hispanohablante.

Tabla 6. Medidas de tendencia central en parámetros actitudinales negativos

\begin{tabular}{|c|c|c|c|c|c|c|c|}
\hline Afirmaciones & $\mathbf{1}$ & $\mathbf{2}$ & $\mathbf{3}$ & $\mathbf{4}$ & $\mathbf{5}$ & $\mathbf{6}$ & $\mathbf{7}$ \\
\hline Moda & 3 & 3 & 5 & 5 & 5 & 5 & 3 \\
\hline Media & 3,46 & 2,89 & 4,57 & 4,24 & 3,48 & 3,96 & 3,06 \\
\hline Desviación estándar & 1,08 & 1,06 & 0,66 & 1,01 & 1,28 & 1,21 & 0,96 \\
\hline
\end{tabular}

Estos resultados permiten afirmar que, si bien los puertorriqueños creen que sus variedades no se corresponden con un ideal de lengua española, no muestran hacia ella posturas estigmatizadoras; cuando se trata de catalogar su variedad negativamente o de no considerarla adecuada para ser empleada en la educación tienden a discordar con la idea.

Por su parte, las afirmaciones agrupadas bajo el rubro «parámetros actitudinales positivos», tuvieron como propósito indagar por el modo en que se manifiestan los antillanos cuando se trata de mostrar conciencia de la lengua como factor identitario, así como el orgullo y la lealtad que sienten hacia su modo de hablar.

El Gráfico 3 advierte que, en general, los puertorriqueños suelen estar Totalmente de acuerdo o De acuerdo con estas afirmaciones, lo cual da muestras de una fuerte actitud positiva ante estas cuestiones. En las afirmaciones 8 y 9 , relacionadas con la idea de la lengua como elemento distinguidor de la identidad y el orgullo hacia la modalidad de lengua que emplean, respectivamente, los puertorriqueños reafirman su preferencia por la opción que refleja una postura extremadamente positiva. La moda en ambos casos es 1 y la desviación estándar de las opciones elegidas en la afirmación 9 evidencia una gran homogeneidad en las respuestas. Si bien en la afirmación 10 no se manifiesta un acuerdo rotundo en relación con la idea de la lealtad y fidelidad hacia su forma de hablar, los resultados también reflejan una actitud positiva en este aspecto. 


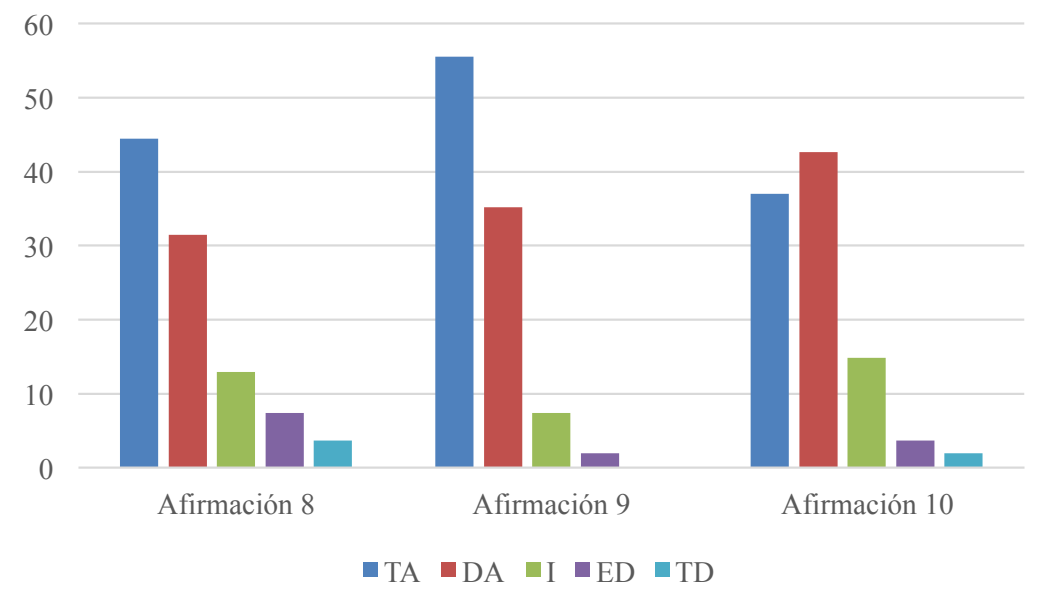

Gráfico 3. Frecuencias relativas de cada opción en parámetros actitudinales positivos

Tabla 7. Medidas de tendencia central en parámetros actitudinales positivos

\begin{tabular}{|c|c|c|c|}
\hline Afirmaciones & $\mathbf{8}$ & $\mathbf{9}$ & $\mathbf{1 0}$ \\
\hline Moda & 1 & 1 & 2 \\
\hline Media & 1,94 & 1,56 & 1,91 \\
\hline Desviación estándar & 1,11 & 0,72 & 0,92 \\
\hline
\end{tabular}

\section{Conclusiones}

La información obtenida acerca de las creencias y percepciones de los hablantes puertorriqueños sobre su variedad de español confirman que, desde el punto de vista cognitivo, los boricuas caracterizan su modo de hablar a través de rasgos lingüísticos que son presentados, en algunos casos, como alejados de un ideal de corrección.

Los resultados expuestos acerca de sus percepciones dialectales dan cuenta de que conciben su variante inserta en un área dialectal en la que incluyen las variedades antillanas vecinas y cuyos límites continentales se extienden hasta Venezuela, Colombia y Panamá, a semejanza de los límites trazados en algunas divisiones dialectales propuestas desde la dialectología tradicional. Asimismo, predomina una percepción marcadamente diferenciadora de las modalidades mexicana, española y de prácticamente todas las del sur del continente. 
Los rasgos tomados en consideración para el establecimiento de las similitudes y diferencias entre variedades evidencian que son los niveles suprasegmental, léxico y fónico los predominantes en la conciencia lingüística de los hablantes para el establecimiento de sus percepciones. El modo en que se presentan tales características también apuntan, en buena medida, a que los puertorriqueños perciben su variedad y el área en la que ella se inserta como alejada de una norma ideal, lo cual se sustenta por el hecho de que algunas de las variedades consideradas como marcadamente diferenciadas, lo son, precisamente, por la corrección que se les atribuye.

Las creencias asociadas a las causas de las similitudes y diferencias lingüísticas evidenciaron que los informantes no suelen reflexionar sobre el tema, en gran medida plantean su desconocimiento o se limitan a no responder. Sin embargo, el proceso de colonización, los orígenes de los grupos étnicos conformadores de las naciones, la ubicación geográfica y los rasgos culturales, son los criterios más tomados en consideración.

No obstante las creencias que vinculan el español de Puerto Rico con usos no prestigiosos o incorrectos, los puertorriqueños muestran una valoración afectiva positiva hacia el propio modo de hablar. Sus reacciones ante las afirmaciones presentadas en la escala Likert muestran que las actitudes lingüísticas del hablante puertorriqueño son muy positivas y evidencian un gran orgullo, lealtad, utilidad y conciencia de que su variedad de español constituye un rasgo imprescindible de su identidad.

En este sentido, este estudio contribuye a reforzar la idea ya apuntada por trabajos anteriores, algunos de ellos comparativos, acerca de la actitud positiva del puertorriqueño hacia su variedad, en relación con las actitudes de sus vecinos antillanos cubanos y dominicanos (Alvar 1986; Sobrino 2017). El peculiar contexto lingüístico de Puerto Rico, sometido al influjo del inglés desde 1898 con la cesión del territorio por parte de España a Estados Unidos, ha sido la causa de que desde inicios del siglo XX se luche contra la oficialidad del inglés en la isla, como un intento de legitimar la identidad propia. Desde septiembre de 2015 se ha vuelto a reconocer solamente el español como lengua oficial en un país que, políticamente, es un Estado Libre Asociado de los Estados Unidos y donde el inglés, a pesar de su gran prestigio, no se ha convertido en una segunda lengua de uso común para la mayoría de los puertorriqueños (González y Ortiz s.f).

A diferencia de sus vecinos antillanos, la convivencia con el inglés de los boricuas condiciona en gran medida su actitud hacia el español (Alvar 1986: 189). 
Los dominicanos y cubanos no viven, como los puertorriqueños, una situación política que a lo largo de su historia ha hecho peligrar el estatus del español como lengua oficial de sus países; por tanto, la expresión de sus opiniones no tiene implicaciones mayores para ellos, como sí para los puertorriqueños, quienes pueden ver en cada oportunidad donde se les aborde al respecto una posibilidad de reafirmación política y cultural.

\section{Bibliografía}

ALBA, O. (1992). "El español del Caribe: unidad frente a diversidad dialectal". Revista de Filología Española 72 (3/4): 525-539.

ALVAR, M. (1982). "Español e inglés. Actitudes lingüísticas en Puerto Rico". Revista de Filología Española 62 (1/2): 1-38.

ALVAR, M. (1986). Hombre, etnia, estado. Actitudes lingüisticas en Hispanoamérica. Madrid: Editorial Gredos.

BLAS ARROYO, J. L. (1999). "Las actitudes hacia la variación intradialectal en la sociolingüística hispánica". Estudios filológicos 34: 47-72.

BLAS ARROYO, J. L. (2005). Sociolingüística del español. Desarrollos y perspectivas en el estudio de la lengua española en contexto social. Madrid: Ediciones Cátedra.

BOOMERSHINE, A. (2006). "Perceiving and processing dialectal variation in Spanish: An exemplar theory approach" en Selected Proceedings of the $8^{\text {th }}$ Hispanic Linguistics Symposium. (Ed. T. Face). Massachusetts: Cascadilla Press: 58-72.

COOPER, R. L. y FISHMAN, J. A. (1974). "A study of language attitudes". Bilingual Review/Revista Bilingüe 4 (1/2): 7-34.

DOMÍNGUEZ, M. (2000). "Los problemas del español del Caribe (Hispánico) (Insular) y la identidad". <http://www.uh.cu/sitios/cat-caribe/images/ficheros/Marlen-A-Dominguez-Hernandez-Los-problemas-del-espannol-delCaribe-\%28Hispanico\%29-\%28Insular\%29-y-la-identidad.pdf $>$. (Acceso 16 Junio 2014).

EMMANUELLI MUÑOZ, M. (1986). Actitudes lingüisticas hacia cuatro fenómenos fonológicos. Tesis de Maestría, Universidad de Puerto Rico, Río Piedras.

EMMANUELLI MUÑOZ, M. (2000). "Valoración social y actuación lingüística hacia algunas variantes fonológicas del español puertorriqueño". Revista de Estudios Hispánicos 27 (1): 209-218. 
ERDÖZOVÁ, Z. (2011). "El español de México en los ojos de sus hablantes. Un estudio desde la sociolingüística y la dialectología perceptiva". Lengua y voz 1 (1): 57-81.

GONZÁLEZ RIVERA, M. y ORTIZ LÓPEZ, L. A. (s. f.). "Política lingüística: Puerto Rico". <https://www.academia.edu/12307402/Pol\%C3\%ADtica ling $\% \mathrm{C} 3 \% \mathrm{BC} \% \mathrm{C} 3 \%$ ADstica_Puerto_Rico $>$. (Acceso 12 Noviembre 2014). HERNÁNDEZ SAMPIERI, R. et al. (2010). Metodología de la investigación. México: Mcgraw-Hill/Interamericana Editores.

HERNÁNDEZ-CAMPOY, J. M. y ALMEIDA, M. (2005). Metodología de la investigación sociolingüistica. Málaga: Comares.

LAMBERT, W. (1964). Social psychology. Englewood Cliffs, N. J.: PrenticeHall.

LIPSKI, J. (2004). El español de América. Madrid: Cátedra.

LÓPEZ MORALES, H. (1979a). "Velarización de /rr/ en el español de Puerto Rico: índices de actitudes y creencias" en Dialectología y Sociolingüística. Temas Puertorriqueños. (Ed. H. López Morales). Madrid: Hispanova de Ediciones: 107-130.

LÓPEZ MORALES, H. (1979b). "Índices de inseguridad lingüística en San Juan" en Dialectología y Sociolingüistica. Temas Puertorriqueños. (Ed. H. López Morales). Madrid: Hispanova de Ediciones: 165-172.

LÓPEZ MORALES, H. (1992). El español del Caribe. Madrid: MAPFRE.

LÓPEZ MORALES, H. (1999). "Anglicismos en el léxico disponible de Puerto Rico" en El Caribe hispánico: perspectivas lingüísticas actuales. Homenaje a Manuel Álvarez Nazario. (Ed. L. A. Ortiz López). Madrid: Iberoamericana: 147-170.

LÓPEZ MORALES, H. (2004). Sociolingüística. Madrid: Gredos.

MOJICA DE LEÓN, C. M. (2014). "Una mirada hacia las actitudes lingüísticas en Puerto Rico" en Actitudes lingüisticas de los hispanohablantes hacia el idioma español y sus variantes. (Eds. A. B. Chiquito y M. A. Quesada). Bergen Language and Linguistics Studies (BeLLS) 5: 1249-1315. <https:// bells.uib.no/bells/article/view/693>. (Acceso 7 Enero 2015).

MONTGOMERY, C. (2012). "The effect of proximity in perceptual dialectology”. Journal of Sociolinguistics 16 (5): 638-668.

MONTIJO, J. A. (2005-2006). "Los vecinos: prejuicio y discrimen en República Dominicana y Puerto Rico". Plaza Crítica 2 (1).

MORALES, A. (2000). "El español de Puerto Rico en su contexto caribeño". Revista de Estudios Hispánicos, U.P.R. 27 (1): 349-359. 
MORENO FERNÁNDEZ, F. (2005). Principios de sociolingüistica y sociología del lenguaje. Barcelona: Ariel.

MORENO FERNÁNDEZ, F. (2009). La lengua española en su geografía. Madrid: Arco/Libros.

MORENO FERNÁNDEZ, F. (2015). "La percepción global de la similitud entre variedades de la lengua española" en Les variations diasystématiques et leurs interdépendances dans les langues romanes. (Eds. K. Jeppesen Kragh y J. Lindschouw). Strasbourg: 217-238.

MORENO FERNÁNDEZ, J. y MORENO FERNÁNDEZ, F. (2002). "Madrid perceptions of regional varieties in Spain" en Handbook of Perceptual Dialectology Vol. 2 (Eds. D. Long y D. Preston). Philadelphia: John Benjamins: 295-320.

PRESTON, D. (1999a). Handbook of perceptual dialectology (Vol. I). Amsterdam: John Benjamins.

PRESTON, D. (1999b). "A language Attitude Analysis of Regional US Speech: Is Northern US English Not Friendly Enough?" Cuadernos de Filología Inglesa 8: 129-146.

QUESADA PACHECO, M. Á. (2010). El español de América. Costa Rica: Editorial Tecnológica de Costa Rica.

QUESADA PACHECO, M. Á. (2013). "División dialectal de Costa Rica según sus hablantes". Dialectología et Geolingüistica 21: 36-69.

QUESADA PACHECO, M. Á. (2014). "División dialectal del español de América según sus hablantes. Análisis dialectológico perceptual". Boletín de Filología 49 (2): 257-309.

REAL ACADEMIA ESPAÑOLA. Diccionario de la lengua española (versión electrónica). <http://www.rae.es/recursos/diccionarios/drae>. (Acceso 4 Agosto 2015).

SERRANO, J. C. (2002). “¿Cuántos dialectos del español existen en México? Ensayo de dialectología perceptual". Manuscrito. $<$ http://lef.colmex.mx/ Sociolinguistica/Cambio\%20y\%20variacion/ Ensayo\%20de\%20dialectologia\%20perceptual.pdf $>$. (Acceso 10 Abril 2015).

SOBRINO, R. (2013). "El español en Cuba según sus hablantes: un acercamiento desde la dialectología perceptiva" en VIII Conferencia Internacional Lingüistica 2013 (CD-Rom). La Habana: Instituto de Literatura y Lingüística "José Antonio Portuondo Valdor".

SOBRINO, R. (2017). Actitudes lingüisticas en el Caribe insular hispánico. Tesis doctoral, Bergen: Universidad de Bergen. 
VALENTÍN-MÁRQUEZ, W. (2006). "La oclusión glotal y la construcción lingüística de identidades sociales en Puerto Rico" en Selected proceeding of the 9th Hispanics Linguistics Symposium. (Eds. N. Segarra y J. Almeida Toribio). Sommerville, MA: Cascadilla Proceedings Project: 326-341.

VAQUERO, M. (1991). "El español de Puerto Rico en su contexto antillano" en El español de América. (Eds. C. Hernández, G. De Granda, C. Hoyos, V. Fernández, D. Dietrick y Y. Carballera). Castilla y León: Junta de Castilla y León, Consejería de Cultura y Turismo: 117-139.

VAQUERO, M. (1996). "Antillas” en Manual de dialectología hispánica. El español de América. (Ed. M. Alvar). Barcelona: Ariel Lingüística: 51-67.

ZAMORA MUNNÉ, J. C. y GUITART, J. M. (1988). Dialectología hispanoamericana. Teoría-descripción-historia. Salamanca: Almar. 


\section{Apéndice}

\section{Cuestionario. Percepciones y actitudes en las Antillas hispanohablantes}

\section{Datos del informante}

¿Usted es de aquí, de la capital?

[ ] Sí [ ] No (pasar a la pregunta 2)

\section{¿Cuántos años lleva viviendo aquí?}

\begin{tabular}{|c|c|c|c|}
\hline PAÍS: & & & \\
\hline Ciudad: & & & \\
\hline Barrio/Suburbio/Zona: & & & \\
\hline Profesión, ocupación u oficio: & & & \\
\hline Sexo: & $\mathrm{M}$ & & \\
\hline Edad: & $20-34$ & $35-54$ & $55+$ \\
\hline $\begin{array}{l}\text { Nivel de instrucción o } \\
\text { educación: }\end{array}$ & Bajo & Medio & Alto __ \\
\hline $\begin{array}{l}\text { Países hispanohablantes que ha } \\
\text { visitado o en los que ha vivido }\end{array}$ & & & \\
\hline
\end{tabular}

\section{Sección 1. Percepciones dialectales}

1. Mencione otros países donde hablan el español de modo similar a como se habla aquí.

2. ¿En qué consisten esas semejanzas?

3. ¿Cuáles cree usted que sean las causas de que existan estas semejanzas?

4. Mencione otros países donde hablan el español de modo diferente a como se habla aquí

5. ¿En qué consisten esas diferencias?

6. ¿Cuáles cree usted que sean las causas de que existan estas diferencias? 


\section{Sección 2. Actitudes lingüísticas}

7. ¿Qué rasgos/características cree usted que permiten reconocer la forma de hablar de su país?

8. Cómo usted tomaría que alguien lo confundiera por su forma de hablar con un: (se descarta el país del informante)

Cubano: Ofensa Cumplido Me resulta indiferente ¿Por qué?

Puertorriqueño: Ofensa__ Cumplido __ Me resulta indiferente ¿Por qué?

Dominicano: Ofensa__ Cumplido __ Me resulta indiferente ¿Por qué?

9. Cómo valora usted la forma de hablar de su país con respecto a la de: (se descarta el país del informante)

Cuba: Mejor __ Peor__ Igual__ No sé____Por qué?

Puerto Rico: Mejor __ Peor__ Igual__ No sé___Por qué?

República Dominicana: Mejor__ Peor__ Igual__ No sé___ ¿Por qué?

10. Caracterice la forma de hablar de los cubanos/puertorriqueños/dominicanos según los siguientes rasgos. Establezca una gradación entre ambos polos tomando en cuenta los números del 1 al 5.

totalmente bastante regular bastante totalmente

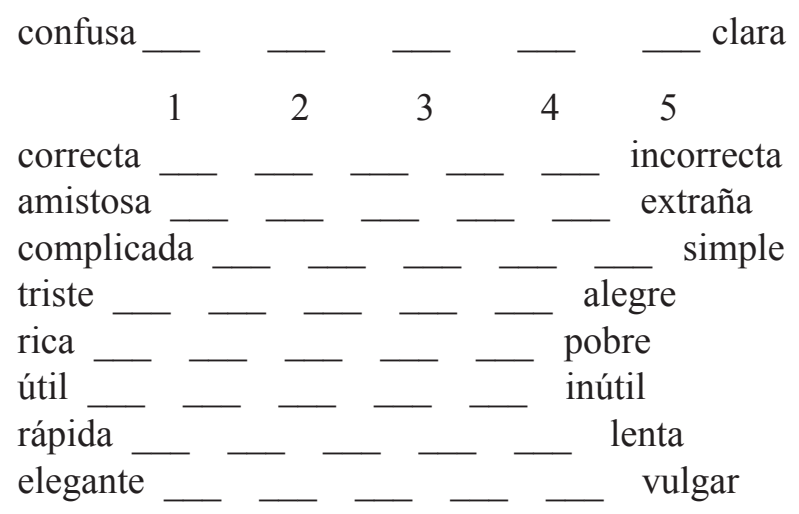


rural urbana

inteligente $\_-\ldots$ torpe

desagradable _- _ _ _ - - agradable

chistosa

seria

11. Sobre las siguientes afirmaciones diga si está Totalmente de acuerdo (TA), De acuerdo (DA), Ni de acuerdo ni en desacuerdo (I), En desacuerdo (ED), Totalmente en desacuerdo (TD):

\begin{tabular}{|c|c|c|c|c|c|c|}
\hline & Afirmaciones & $\mathbf{T A}$ & DA & I & ED & TD \\
\hline 1 & $\begin{array}{l}\text { Los cubanos/puertorriqueños/dominicanos } \\
\text { pronunciamos muy mal }\end{array}$ & & & & & \\
\hline 2 & $\begin{array}{l}\text { Cuando hablo con personas de otros países } \\
\text { cambio mi manera de hablar }\end{array}$ & & & & & \\
\hline 3 & $\begin{array}{l}\text { Mi modo de hablar me identifica con los de } \\
\text { mi país }\end{array}$ & & & & & \\
\hline 4 & $\begin{array}{l}\text { El español que se habla en las Antillas es el } \\
\text { peor español }\end{array}$ & & & & & \\
\hline 5 & $\begin{array}{l}\text { Nosotros hablamos un peor español porque } \\
\text { somos un país pobre }\end{array}$ & & & & & \\
\hline 6 & $\begin{array}{l}\text { Es muy difícil distinguir a un cubano, un } \\
\text { dominicano y un puertorriqueño por su forma } \\
\text { de hablar }\end{array}$ & & & & & \\
\hline 7 & Nunca cambiaría mi forma de hablar & & & & & \\
\hline 8 & $\begin{array}{l}\text { En mi país se habla con muchas } \\
\text { incorrecciones }\end{array}$ & & & & & \\
\hline 9 & $\begin{array}{l}\text { El español de mi país no se debe enseñar en } \\
\text { las escuelas }\end{array}$ & & & & & \\
\hline 10 & $\begin{array}{l}\text { Me siento muy orgulloso de mi forma de } \\
\text { hablar }\end{array}$ & & & & & \\
\hline 11 & Me trae beneficios no hablar como los de aquí & & & & & \\
\hline 12 & $\begin{array}{l}\text { A las personas de los demás países no les } \\
\text { gusta como se habla aquí }\end{array}$ & & & & & \\
\hline 13 & $\begin{array}{l}\text { En mi país existen diferencias en el modo de } \\
\text { hablar el español según el color de la piel }\end{array}$ & & & & & \\
\hline
\end{tabular}

